\title{
The Contemporary Linguistic Personality in the Public InfoSphere
}

\author{
O. E. Gaibaryan \\ Cand. of Sc.( Philology) \\ South Federal University \\ Rostov-on-Don,Russia \\ oc41@bk.ru
}

\author{
G. I. Myasischev \\ Don State Technical University \\ Rostov-on-Don,Russia \\ georgy-2583@yandex.ru
}

\begin{abstract}
The article deals with the behavior of the linguistic personality in the modern information space. The main directions of pragmatic study are determined. A review of the interaction of linguistic personality and information flow in the communicative field is given. In the article we show how the modern linguistic personality chooses the source of information. We research the evaluation of the modern information. The article is based on actual and extensive statistical material. Linguistic personality in public communication reflects objectively existing features of the culture of information possession and can actively influence the development of linguistic community, increasing interest in various areas of social activity, which contributes to the formation of specific information spaces in the public communication space. The article emphasizes that in the context of globalization of the communication space in the Internet environment it becomes obvious that the view of many processes and phenomena in both socio-political and cultural, economic, etc. areas and their assessment have changed significantly, and the ability to manage information flows has been transformed.
\end{abstract}

Keywords - linguistic personality, information culture, theory of linguistic

\section{INTRODUCTION}

The role that information plays in the public activity of the linguistic personality is extremely important. In fact, we may speak about the essential structure of the linguistic personality which exists in their speech practice thanks to the process of perception, generating, determining, and evaluating a variety of data by linguistic means. The importance of studying the part the information plays via the linguistic personality`s speech manifestation in the contemporary public environment is quite high because the information flow produced and determined by the linguistic personality features a purely non-material value which determines the man`s life in its every economic, social, and cultural aspects.

This work aims to presenting the results of studying the evolution of the public discourse infosphere in view of the interaction between information and the linguistic personality. The authors had not claim to expose the whole wide spectrum of the problem within the limited size of the article; they just mean to share the results of their research in this particular direction.

\section{INFORMATIONAL BEHAVIOR OF LINGUISTIC PERSONALITY}

An analysis of some theoretical works in the sphere of the interrelated language and culture training has shown that the issues of forming the linguistic personality are beginning to play a leading part in methodological studies. In the latest decades, the focus of the researchers has shifted to the following problems:

- the development of the secondary linguistic personality theoretical basis in the process of learning foreign languages by the students of language colleges (I.I. Khaleyeva, [1]; I.B. Ignatova [2]);

- a joint study of a foreign language and culture in the framework of forming the linguistic personality as crosscultural character or cultural mediator, mostly oriented at effective cross-cultural communication (G.V. Yelizarova [3]; O.A. Leontovich [4]; S.Bochner [5]; P.S.Adler [6]; S.Dahl [7]);

- the development of the theoretical background of a sociocultural approach to teaching the languages of international communication, practical techniques of its introduction in general education schools and colleges (E. I. Passov [8]; O. G. Orlova [9] ; N. L. Michalina[10]).

The researchers deal with some factors that control information behavior at the entrance and exit of the information flow in the process of the public space communication. Group communication presupposes delegating the functions of verifying, determining, and control to each participant of the intercourse. At that, only few participants here prove the whole functionality while the others hardly use one or few of the functions.

On the one hand, the public conscience reflects demand of the information generated by the society progress, while on the other hand, by applying a specific analysis one may register "the final stage of conversion" of this demand, i.e. the preferences of social information are manifested in the audience behavior by choosing of sources, specific materials, programs. 
The objective strive for information indirectly controls the man`s attitudes towards it: the first step of the information objective requirement transfer into the person's inner structure is necessity. "If the urges arising from interests are described via images, signs, symbols and, being related to concepts, may be transmitted via a language, then the needs are not directly expressed in the language" [1,11-13].

In terms of information acquired by the man, along with the social progress the most important role gets played by the information, that the man acquires by implication immediately in the process of his own practical activity, or diluted in the proximate personal communication with others but the one organized in information channels.

Even though the processes of reflecting the reality are more related to social information bonds, the linguistic personality proper remains an active subject of perception. As the subject of perception the man determines himself like the most part of his information behavior, the objective background of which is the demand of information.

The requirement of information reflects the social necessity of information support for virtually every sort of activity in the subject's structure. Moreover, it predetermines the inclusion of the subject in the existing information systems of the society.

Historically, consumption of information is tightly entwined in the fabric of any activity and is inseparable from it. "The production of ideas, concepts, consciousness is originally interlaced with the human material activity and material communication, with the real life language" [11]. This statement has an important methodological value not only for a wide spectrum of independence, but for the level of the formedness of information activity as something separate both historically and morphologically.

Like any other kind of activity, information activity is regulated by social needs and social groups interests. Being a subject of social needs and interests, information is included in the system of social and, as of now, economic values. This value gets its own socio-cultural or professional interpretation, promoted, acquired at various communicative levels, especially in social environment. Possession of information is becoming a most vital factor.

The relationship between the person and the information system may acquire functional and dysfunctional characteristics. Starting in the 1970s, the existence of a special type of dysfunctional attitude towards information has been determined by science. The bearer of this type was specified in sociology as a strictly consuming personality ("homo consumens") [14]. Their key direction was "not production or creation but consumption of material and standardized massculture values that are hardly utilized in their true implication but, instead, are acquired as the symbols of external social or psychological well-being". The information boom arising after the mass spread of the Internet and the oncoming of such specific information phenomena as social networks, theme or multi-segment forums etc. gave birth to the mass consumption of information, manipulation by a person or group by means of a specifically verified flow, substitution of an information constituent with a different information content $[15,16]$.
In this case, the dysfunction of information flow directly affects the person by breeding the inability to correctly determine and appreciate the information which is coded by means of a natural language and, consequently, generating secondary false flows that have no real value due to the loss by the linguistic personality of objective control over the semantic and formal content of the communicative field by value-based information constructions [17-19].

The advent of this phenomenon in the form of sociopsychological and linguistic actors named trolls, haters, logs etc., in group communications of the Internet are particularly due to the problems of diversification of the information value of messages within communication interaction and communication itself. Decoding the social, cultural or other status with this or another information content without adequate determination and evaluation of the latter may result in destructing the individual's ability to recognize a valuebased information flow [17].

As a example let us take the statement of a person that pretends being an expert in the field: "The existence of the Old Russia language should be proven eloquently. The term "old" relates to antiquity, however in the 5th century we only had shepherds roaming round here". Quite evidently here, the negation of the mere fact of existence of the Old Russia language is of a peculiarly demonstrative nature thus intending to report something new and also to strengthen the status of the "expert". Fake information that is designed to persuade the public, a priori with a lower IQ, proves the author`s inability to critically accept their own thesis and relate it with some basic wide-spread popular knowledge about the subject of discussion. In this case, the linguistic personality produces false stories on the subject and also attempts to shows their doubtful superiority in the intellectual and communicative spectrum. Thus, the consumer attitude to the information as part of public communication and the relating status of the communicant devalues the concept of information and communication as a means of information exchange. In case trustworthy information may not acquired via public communication, then, accordingly, public communication gets discredited in this respect.

\section{EVALUATION METHODS AND SOURCES OF INFORMATION}

Consequently, there arises an issue about the source of information.

In 2008, there came a judgement related to the International Law where some social network data was used as an information (content) constituent of the argument at the level of the public discourse among top governmental officials. Further on in the 2014-17, some social network data was discussed as a source of trustworthy information both at the governmental and wide public levels.

Thus, nowadays it is hardly possible to tell reliable information sources from a priori fake ones judging by their origin. There are equal chances that any made-public information in the Internet or leading newspapers, or transmitted otherwise may be reliable or false. The multiple cases relating to the "expert" publications with clearly pseudoscientific or utterly false content thus intentionally 
misinforming the user, facilitate uncertainty and instability in the area of receiving and further utilization as well as verification of secondary information.

With that in mind, the linguistic persona is forced to accept the function of expert judgment of the information received and, accordingly, verified. Since the linguistic personality is often present in the direct information flow directly involved in public (business, social, professional, general cultural) communication, the time for judgment is too short. Therefore, the contemporary linguistic personality is forced either to restrict their professional or social interaction by joining purely profile forums or by developing a widest outlook along with the ability to directly perceive, estimate, and correctly interpret information within the communication process.

The society utilizes some technologically reliable and sophisticated mobile and other available channels of control, e.g. the Internet, press, radio and TV. They act not only as the direct means of journalistic impact but also as the information sources of social, institutional, administrative, and culturalpsychological control [20].

For each of the above types of activity, information serves as "the key attribute of the process of control" by ensuring and servicing every stage of the process. Within the framework of each type, one may find some specific types of information with the essence and form being determined by its activity. The linguistic personality being in the infosphere of a public discourse sets up the concept of social reality as a whole by counteracting the isolation of some activities and the spatial dissociation of some social groups. In this connection, the level of marginality and the low competence of the linguistic personality or a social group or the whole of the society (e,g, a Russian-speaking linguistic personality as the complex of all the features of Russian language speaking individuals) plays a leading part in the ability to verify, determine, and appraise information.

It is customary that the higher the level of education, the more critical is the attitude of the public about the essence of the information flow. However, our study shows the opposite. The phenomenon of the availability and distribution of pseudoscientific theories in the society and the power of their impact via translating some predeterminedly fake information proves the virtually equal vulnerability of all of the groups irrespective of diplomas and levels of training.

The authors of this article have studied the linguistic persona`s ability to perceive, diversify, evaluate, and critically digest the information they acquire.

The survey was performed on a variety of social groups: senior students of humanities (economics, architecture, design 45 persons), and engineering sciences (civil construction - 58 students), the faculty of a Russian university (24 persons), volunteers from the "Litset", the literary Internet-based forum (32 persons).

The choice of target groups was predetermined by the authors`aim to study various social and status groups that have an access to a spectrum of information sources, exposed to a wide variety of impacts from the environment, possess different walks of life and communication experience. The choice of the literary portal was made basing on the prerequisite that the members should be from different social groups, professions, and featuring different world outlooks. Having various, unknown to the researchers, levels of education, but united by a single interest in fiction and a certain amount of communicative experience of working with the word, as well as the need of communication in the general literary environment. This enables us to make restrictions in the marginalization and socialization of the group, to cut off the extreme forms of linguistic communication and to study the generalized linguistic personality that is familiar with the language and literature in the direct communication sphere.

The information sources of the public space have been estimated by the members of the questionnaire based on the demand criteria, applicability (usage convenience) and resource intensity (the level on satisfying the reader's needs with the information content as percentage of the number of sources used)

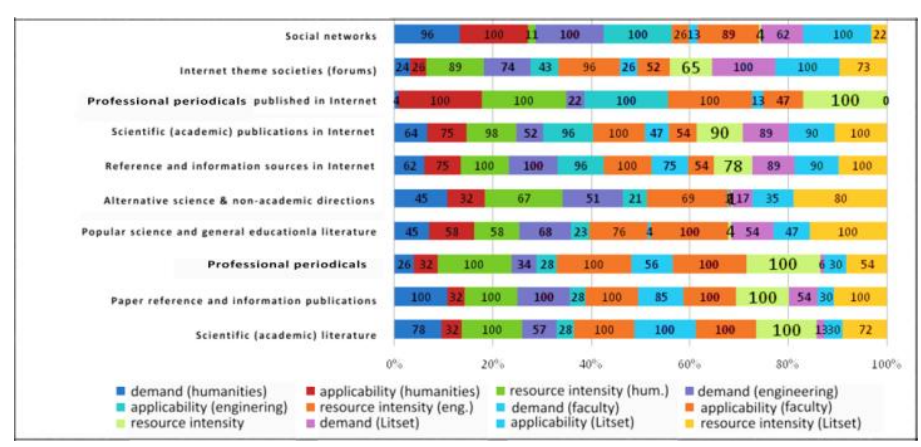

Pic. 1. A Study of the Choice of an Information Source

The study shows that, as expected, academic and reference literature is in demand among the students and faculty. Professional periodicals are in lower demand and, according to the participants, are mainly used by those students and instructors who possess some applied practical experience. An unexpectedly high level of trust has been shown among the students to the alternative science and non-academic publications. This may allow us to speak of certain skepticism about scientific knowledge (using academic sources only for academic purposes or when looking for alternatives) and also of small scientific and practical experience. The high demand of Internet information was originally expected among the students and the visitors of the literary portal (even though the latter use paper editions to add to those retrieved from the Internet). However, about half of the scientific-and- teaching communities involved are willing to apply up-to-date information technologies. The researchers were surprised at the unexpectedly good results about using social networks for information which testifies about the nonseparatedness of the sources and a certain amount of trust to the printed word disregarding the source. Some additional questions asked individually revealed the low percentage of trust among the instructors of humanities to the profile theme Internet communities due to caused by distrust to the information they publish, mostly because of the untrustworthy authors, even though most respondents admitted that they had never been familiar to them. The personalization of unwillingness to 
contact at such profile sources seems like a personal defense from any possible criticism on the part of the participants of the society (about $11 \%$ of both groups of those who showed distrust), a feeling of a priori superiority (18\% of the faculty and $13 \%$ of the students), hardship relating to distant communication on scientific theme questions (7 and $10 \%$ respectively). The rest of the respondents had problem giving straightforward answers and reported some communicative discomfort and even total distrust to that sort of sources. It's noteworthy that all of the groups, unwilling to communicate in profile sources; never have problem communicating in social networks. The authors feel there's a certain psychological communication barrier, particularly located in the lingvocommunication field that interferes with the manifestation of the linguistic persona's communication opportunities specifically in the profile environment. The linguistic persona is treated not only as a communicating subject but also as a modus of values capable of affecting an individual. This means that in an a priori equal medium, void of some restraining social barriers (rank, position, age, mode of behavior, social role) the individual experiences a substantial evaluating impact they're not prepared for. The reason of discomfort here lies in the absence of a sound array of tools of communicatorypersonal impact and the ability to defend their own point of view via communication. Thus, the profile medium is perceived as unfavorable, never allowing the linguistic persona to reach a wholesome self-realization. Interestingly, the engineering students and those instructors who have experienced in production have never faced such problems because of lack of fear of the consequences relating to losing reputation because, according to them, they are capable of keeping communication within the given practical framework and never diversify the information exchange in the personality-reputation field. The authors` research indirectly confirms the data of high aggressiveness in the humanitarian communication medium in particular and expressed lack of tolerance in the profile societies of such type.

So, the choice of the source of information is mostly defined not by how relevant or applicable but how psychologically and communicatively (lingvocommunicatively) convenient it is.

\section{ASSESSMENT OF THE QUALITY OF INFORMATION BY A LINGUISTIC PERSONALITY}

Distribution in terms of convenience of using a source indicates that all of the age categories involved make use of contemporary information technologies. Limitations here are only due to the user's level of training and their desire to use them. Among the participants was an 88-year-old professor of a Russian engineering college who gladly use the Internet for searching and publishing scientific information; there are also a few young people aged 17-24 who have difficulty performing easiest operations with search systems and network content.

We have also studied the value-based perception of information flow during a public-discourse communication from the angle of how the contemporary linguistic persona gets manifested themselves. This analysis has enabled us to collect the data shown below that reflects attitudes to some various content indices and the design of the information flow of the linguistic persona.

TABLE 2. ANALYSIS OF ASSESSMENT OF ACQUIRED INFORMATION

\begin{tabular}{|c|c|c|c|c|}
\hline \multirow[t]{2}{*}{ Index } & \multicolumn{4}{|c|}{$\begin{array}{l}\% \text { of the total number of participants in } \\
\text { each group }\end{array}$} \\
\hline & $\begin{array}{l}\text { Student } \\
\text { s of } \\
\text { humani } \\
\text { ties }\end{array}$ & $\begin{array}{l}\text { Engine } \\
\text { ering } \\
\text { student } \\
\mathrm{s}\end{array}$ & Faculty & $\begin{array}{l}\text { "Litset" } \\
\text { Forum } \\
\text { participa } \\
\text { nts }\end{array}$ \\
\hline Relevance & 16 & 34 & 41 & 11 \\
\hline Objectivity & 86 & 74 & 100 & 54 \\
\hline Authenticity & 65 & 78 & 100 & 43 \\
\hline Completeness & 31 & 22 & 69 & 61 \\
\hline Significance & 64 & 68 & 73 & 96 \\
\hline Importance & 100 & 100 & 100 & 100 \\
\hline Accessibility & 49 & 63 & 12 & 98 \\
\hline Availability of facts & 24 & 43 & 78 & 35 \\
\hline $\begin{array}{l}\text { Emotionality of } \\
\text { presentation }\end{array}$ & 35 & 19 & 9 & 57 \\
\hline \multicolumn{5}{|l|}{ Narrative style } \\
\hline academic & 22 & 19 & 34 & 11 \\
\hline business & 25 & 32 & 27 & 21 \\
\hline $\begin{array}{l}\text { professional } \\
\text { (highly specific) }\end{array}$ & 45 & 26 & 39 & 28 \\
\hline everyday & 9 & 11 & 1 & 19 \\
\hline sub-cultural & 10 & 12 & 0 & 21 \\
\hline $\begin{array}{l}\text { Speech } \\
\text { formalization }\end{array}$ & \\
\hline literacy & 32 & 13 & 53 & 16 \\
\hline $\begin{array}{l}\text { richness of } \\
\text { content }\end{array}$ & 35 & 43 & 68 & 72 \\
\hline accentuation & 29 & 11 & 9 & 14 \\
\hline
\end{tabular}

Consequently, we may note that for every participant the importance of information is the most critical parameter, but at that the process of verification and presentation of the public discourse content is estimated differently. The students of humanities are mostly inclined to evaluate information from the angle of its emotional effect; they admit some specific styles of narration that are typical of subcultures, but, on the other hand, they are more sensitive to the formal parameters of speech. The would-be engineers are more careful about the content of the data received, the way of its verification; however, they are softer on the formal parameters of speech. The faculty is quite demanding about the content and factrichness of information, but seems relatively loyal to its formal characteristics.

Finally, the Internet medium with its millions of users has no clear-cut socio-professional distribution, thus being least sensitive to the information flow content but most demanding about the emotional-evaluating side of the information presented by the linguistic persona.

\section{CONCLUSION}

Being in the infosphere, the contemporary linguistic personality gets involved in the direct info flow verification and evaluation processes. More critical for the realization of 
the linguistic persona`s abilities is still a reputable source of information; at that, the linguistic persona shows their general vulnerability towards fake knowledge and manipulation techniques. The importance of the information content of realizing the linguistic persona in public discourse is getting more and more important, but the quality of information is degrading being replaced with emotional and communicative contents as a goal in it. Moreover, the information constituent gets filled with some formalized linguistic content that has nothing to do with the essence of the subject or objective reality. Here we may observe the phenomenon of the information flow virtualization that results in the complete substitution of objective reality by illusions. Accordingly, the linguistic persona gets modified and presented differently in different, formally close or identical media. At that, the individual accepts a certain mode of speech behavior (linguistic personality) and generates information that is required not by objective reality but by their mode of behavior and the communicative situation they are in. For instance, a college instructor, normally generating competent and trustworthy knowledge, may join an expressly quasi-scientific society in the social network and become one of the members of communication. As a result, the role nature of the contemporary public communication affects both the linguistic persona`s nature and the information they generate.

Considering the above, information and the linguistic personality are closely interrelated to act throughout the whole period of its communicative life.

\section{REFERENCES}

[1] I. I. Khaleeva Understanding the foreign-language spoken text as an aspect of inter-cultural communication. Looking into the future. The first Soviet-American Symposium on teretic problems of teaching and learning foreign languages. 17-21 X. 89. M.: REMUS, the MIST, 1992. pp. 20-127.

[2] I. B. Ignatova 1997 Teaching the grammatical structure of the Russian speech of foreign students-philologists as the basis for the formation of the language personality of the future teacher: autoref. dis... Doc-PAED. sciences'.(SPb.,) p.32

[3] G. V. Elizarova 2001 Culture and foreign language training (St. Petersburg: publishing house "Soyuz") p. 291

[4] O. A. Leontovich 2003 Russia and the United States: an Introduction to cross-cultural communication (Volgograd: Peremena) p. 398

[5] S.Bohner 1972 Problems in cultural learning. Overseas students in Australia (Sydney: New South Wales University Press) pp. 33-41.

[6] P.S. Adler Beyond Cultural Identity: Reflections on Cultural and Multicultural Man. Culture, communication and conflict: readings in inter-cultural relations 1998, vol.16, pp. 250-265.

[7] S.Dahl 1998 Communications and culture transformations. Cultural diversity, globalization and cultural convergence. Project presented to the European University (Barcelona)

[8] E. I. Passov 2000 The program-the concept of communicative foreign language education ( M.: Education) p.176

[9] O. G. Orlova 2005 Actualization of the concept "Russia" ("Russia") in American journalism (on the example of the discourse of the weekly "Newsweek"): author. dis.... kand. Philol. sciences'.(Kemerovo) p. 20

[10] N.L. Michalina 2000 Lingvokulturologicheskom approach to the development of speech of pupils of the VII-IX classes: Avtoref. dis. ... kand. PED. sciences'.(SPb) p. 22

[11] A. A. Leontev 1997 Fundamentals of psycholinguistics. (M.: Sense) p. 287

[12] G I Goddess 2010 The Model of Linguistic persona and Its Relation to Different Types of Texts (Moscow) $144 \mathrm{p}$

[13] Yu Karaulov 2004 The Russian Linguistic Persona and Challenges of Studying It (Moscow) $228 \mathrm{p}$

[14] M Y Bloch 2004 Pragmatism, Ethics and Aesthetics of Communication. Linguistics and language education in modern Russia (Moscow) p 43-67

[15] I A Sokolov 2007 PhD Thesis abstract (Moscow) $28 \mathrm{p}$

[16] O V Kliuchnikova and Pobegaylov O A 2016 Procedia Engineering 150 pp $2168-2172$

[17] O A Pobegaylov, G I Myasishchev and O E Gaybarian 2016 Procedia Engineering 150 pp 2173-2177

[18] K A Abulkhanova 1997 Russian mentality: cross-cultural and typological approaches // Russian mentality: issues of psychological theory and practice (Moscow: Institute of psychology RAS) p 37

[19] A A Leont'ev 2012 Psychophysiological mechanisms of speech. General linguistics: forms of existence, function, language history (Moscow) pp 314-375

[20] T E Vladimirova 2010 Called into the fellowship: the Russian discourse in the intercultural communication (Moscow: Book house "LIBROKOM") 56 p.. 